\title{
Structural and Optical Studies of Nano-structure Monolithic Silica-Gel Derived Glasses Containing $\mathbf{N d}^{3+}$
}

\author{
I. K. Battisha \\ Solid State Physics Department, National Research Center (NRC), Cairo, Egypt
}

The sol-gel process was applied for the preparation of neodymium $\left(\mathrm{Nd}^{3+}\right)$ doped silica gel derived glasses. Two different procedures have been studied using two different precursor materials, Tetramethoxy-silane (TMOS) and Tetraethoxy-silane (TEOS), giving silica gel and silica doped with $\mathrm{Nd}^{3+}$ of type I and type II, respectively. Both type materials were subjected to the same heattreatment temperature. The normal transmission was measured using Fourier Transform Infrared Spectrometer FTIR, Raman analysis and X-ray diffraction $(X R D)$, were carried out to determine the crystal structure of the prepared samples. The prepared samples change from amorphous to $\alpha$-crystoballite phase at higher temperature regardless the two type materials. The crystallite size was found to be as small as $10.4 \mathrm{~nm}$ at $1400^{\circ} \mathrm{C}$ for pure sample type II. The thermally treated sample microstructures were investigated using scanning and transmission electron microscope. Also DTA and TGA Characteristic techniques were used. The photoluminescence PL measurements for pure sample (type I) heat-treated at $1400^{\circ} \mathrm{C}$ shows bands of maximum in the blue green spectral region at 535 and $546 \mathrm{~nm}$ accompanied with band of weak intensity at $590 \mathrm{~nm}$. Doped sample (type I) heat-treated at $1400^{\circ} \mathrm{C}$ shows new bigger, sharper and intense bands at 875,889 and $900 \mathrm{~nm}$ that were interpreted on the light of $4 F_{3 / 2}$ to $4 I_{9 / 2}$ transitions of $\mathrm{Nd}^{3+}$ ion. PL spectra are found to be sensitive to defects such as impurities and E' centers. 


\section{Introduction}

Nanoparticle silica-gel derived glsasses is an attractive amorphous material, that is applied, as a wave-guide [1], chemical gas sensor [2] and so on. It can be prepared by sol-gel method, which is being actively studied in leading laboratories all over the world [3]. The advantage of this process is to avoid generation of dangerous dust, as would be produced in conventional ceramics processing. The primary attention was paid to its low temperature nature [4-11].

One of the major advantages of the sol-gel process is the possibility to prepare multi-component systems. The glasses in the system $\mathrm{SiO}_{2}-\mathrm{Nd}_{2} \mathrm{O}_{3}$ posses many favorable properties as thermo-stable medium for optical performance. Previous coworkers [9] successfully obtained neodymium doped silica glass containing up to $20 \mathrm{wt} \% \mathrm{Nd}_{2} \mathrm{O}_{3}$ using the sol-gel process. They suggested oxygen coordination number to be 6 around neodymium. Although the sol-gel process allows the preparation of glasses with much higher concentrations of neodymium the problem of microscopic clustering remains even if some other appropriated components are added. That is why further research is required to understand more fully the local environment of neodymium in silica glass.

Rare earth ions are used as dopants in glasses mainly for two reasons. the first one is their well defined and sharp energy levels, which may serve as structural probes for the environment of the dopants, and the other one is the modifications of the energy level structure of the rare earth ions caused by the glassy environment may lead to interesting applications, e.g., solid state lasers [12]. The glass compositions are more favorable for high-density memory devices, because the inhomogeneous widths of the transition between the energy levels are much broader than those of crystals. In addition, the high transparency and easy mass production are also particularly promising for practical application in optical device [13].

In the present work, nano-structure monolithic silica gel derived glasses pure and doped with $\mathrm{Nd}^{3+}$ ion using two different precursor materials TMOS and TEOS, were succefully prepared by a simple sol-gel method. The effect of increasing the heat-treatment temperature on the microstructure of the prepared samples was studied. The data are presented for the structure evolution of pure and doped samples by XRD, the transmission FTIR and Raman spectroscopy $[14,15]$. Scanning and transmission electron microscope studied the morphology and the microstructure of the prepared samples. DTA and TGA techniques were used with increasing the temperature up to $1000^{\circ} \mathrm{C}[16,9]$. The PL spectra were found to be sensitive to the defects in the bulk materials, it had made possible the extensive characterization of radiation recombination processes through the intrinsic defects in this materials. 


\section{Experimental}

Pure silica gels and silica gel doped with neodymium $\left(\mathrm{Nd}^{3+}\right)$ were prepared using two different procedures via the hydrolysis and condensation of two different precursor materials TMOS and TEOS. The first procedure is prepared from $\left(\mathrm{CH}_{3} \mathrm{O}\right)_{4} \mathrm{Si}$ (Tetramethoxy-silane) TMOS, methanol and distilled water, in the presence of nitric acid (type I). The second one is prepared from $\left(\mathrm{CH}_{3} \mathrm{CH}_{2} \mathrm{O}\right)_{4} \mathrm{Si}$ (Tetraethoxy-silane) TEOS, ethanol and distilled water, in the presence of hydrochloric acid (type II). The overall process can be written as:

$$
\begin{aligned}
& \mathrm{Si}(\mathrm{O}-\mathrm{R})_{4}+4 \mathrm{H}_{2} \mathrm{O}-------\mathrm{Si}(\mathrm{OH})_{4}+4 \mathrm{C}_{2} \mathrm{H}_{5} \mathrm{OH} \quad\left(\mathrm{R}=\mathrm{CH}_{3} \text { or } \mathrm{CH}_{2} \mathrm{CH}_{3}\right) \\
& \mathrm{Si}(\mathrm{OH})_{4}--------\mathrm{SiO}_{2}+2 \mathrm{H}_{2} \mathrm{O}
\end{aligned}
$$

The molar ratio in the starting solution was 0.44: 0.25: 0.074: 0.052 : 0.001 for $\mathrm{H}_{2} \mathrm{O}: \mathrm{CH}_{3} \mathrm{OH}: \mathrm{HNO}_{3}$ : TMOS: $\mathrm{Nd}_{2} \mathrm{O}_{3}$, and 0.39: 0.152: 0.0823: 0.028: 0.001 for $\mathrm{H}_{2} \mathrm{O}: \mathrm{C}_{2} \mathrm{H}_{5} \mathrm{OH}$ : $\mathrm{HCl}$ : TEOS: $\mathrm{Nd}_{2} \mathrm{O}_{3}$. Neodymium was introduced in the initial stage of the process, by dissolving $0.137 \mathrm{~g}$. of neodymium oxide in nitric acid under heating, resulting in a clear violet solution then the precipitate is dissolved in the silica sol-gel solution prepared before. This solution is then filtered, followed by stirring for one hour at room temperature. The resultant homogeneous solutions were filled in a mould and placed in a drying oven type GFL 7105 at $60^{\circ} \mathrm{C}$. The gelation act after approximately 2 days by using TMOS and after about 4 days by using TEOS. The final products were monolithic cubes $15 \times 15 \times 3 \mathrm{~mm}$. All samples were clear and transparent. The pure samples are colorless and the samples containing neodymium have violet color. After gelation the samples were still left inside the oven for 21 days for aging (which result in a further shrinkage and stiffening of the gel), until no shrinkage appear. Densification of the prepared glass samples was obtained by annealing in air for two hours at temperature ranging from 300 up to $1500^{\circ} \mathrm{C}$ in a muffle furnace type (Lento) with heating rate $1.5^{\circ} \mathrm{C} / \mathrm{min}$.

The X-ray diffraction (XRD) patterns of the prepared samples were recorded with X'Pert-Philips X-ray diffractometer with monochromatised $\mathrm{CuK}_{\alpha}$ radiation of wavelength $1.5406 \AA$ at $55 \mathrm{kV}$ and $40 \mathrm{~mA}$. The crystallite size was calculated applying fourrier analysis after correcting the diffraction data for the instrumental broadening using $\mathrm{LaB}_{6}$ as a standard material (win fit program).

FTIR study of the two types I and II was performed with a Perkin Elmer 1600 (spectrophotometer) in the $4000-100 \mathrm{~cm}^{-1}$ region. Raman spectra were recorded using BRUKER IFS 6/S with Nd-Yag with wavelength $1.064 \mu \mathrm{m}$ laser as light source. The surface morphology and microstructure of the prepared samples was evaluated using scanning electron microscope (SEM) (JEOL JSMT330 A) and transmission electron microscope (TEM) [EM 10 Zeis] respectively. The weight loss Endothermic peaks were performed using thermal 
gravitational analysis (Shimadzu TGA and DTA 50), from room temperature up to $1000^{\circ} \mathrm{C}$ under inert gas, $\mathrm{N} 2$ with $10^{\circ} \mathrm{C} /$ minute. Optical transmission spectra for the prepared samples were measured using Jasco V-570 spectrophotometer, in wavelength range (400-1000) $\mathrm{nm}$ The PL emission obtained using luminescence spectra JASCO FP-777 conventional spectrofluorimeter. The 488 $\mathrm{nm}$ line of a spectra-Physics 2017 Argon laser was used to excite room temperature luminescence spectra. A fiber optic probe coupled to a Dilar Superhead, equipped with a suitable notch filter, was employed. A 150 lines $/ \mathrm{mm}$ grating was used for measuring laser excited luminescence spectra.

\section{Results and discussion}

The effect of heat treatment temperature on the structure of the prepared pure silica gel derived glasses and doped with $\mathrm{Nd}^{3+}$ ion (type I\&II) is shown in Figure (1). No peaks are observed in samples fired below $1050^{\circ} \mathrm{C}$ (type II) except for the harrow-like pattern at $2 \theta$ between 12 and $24^{\circ}$ attributed to amorphous silica gel. However, a small and broad peak at $2 \theta$ between 26 and $26.4^{\circ}$ in the samples containing $\mathrm{Nd}^{3+}$ (type II) appears after firing the samples at $1050^{\circ} \mathrm{C}$ for 2 hours, which may be ascribed to preliminarily crystallization of samples. While at $1300^{\circ} \mathrm{C}$ two broad and small peaks at $2 \theta=21.9$ and $31.4^{\circ}$ appeared, can be indexed as (101) and (102) diffraction principle line of tetragonal alpha crystobalite respectively, indicating the beginning of crystallization. Which shifted at higher temperature up to $1500{ }^{\circ} \mathrm{C}$ in pure and doped samples (types I and II) to $2 \theta=22$ and $31.5^{\circ}$ indexed as (101) and (102), also new peaks appeared at $2 \theta=25.2,28.4$ and $36.4^{\circ}$ indexed as (110), (111) and (112) diffraction principle line of tetragonal alpha crystobalite (JCPDS card num. 82-1403). A peak at $2 \theta=28^{\circ}$ with no defined phase was appeared. A similar suggestion was done by Bouajaj [14], who found that, at $1300^{\circ} \mathrm{C}$ the silica xerogels partially crystallize in the $\alpha$-crystoballite phase as detected by the Raman analysis. The XRD patterns of prepared samples type I showed the same peak positions as type II with different intensities, (accordingly we found it is unnecessary to go in small steps in pure samples, so we took the sample treated at $1500^{\circ} \mathrm{C}$ to compare it with that of the two doped types). It is observed that, by increasing the heat treatment temperature both the intensity of the peaks increases and the broadening decreases, indicating the enhancement of crystallinity. While both of them decreased by doping the sample with $\mathrm{Nd}^{3+}$ than the pure one regardless the two type materials. At $1500^{\circ} \mathrm{C}$, the peak intensities of doped sample type II decrease than the peak intensities of doped sample type I. The calculated crystallite size from XRD data; for pure sample heat treated at $1400{ }^{\circ} \mathrm{C}$ was as small as $10.4 \mathrm{~nm}$. 


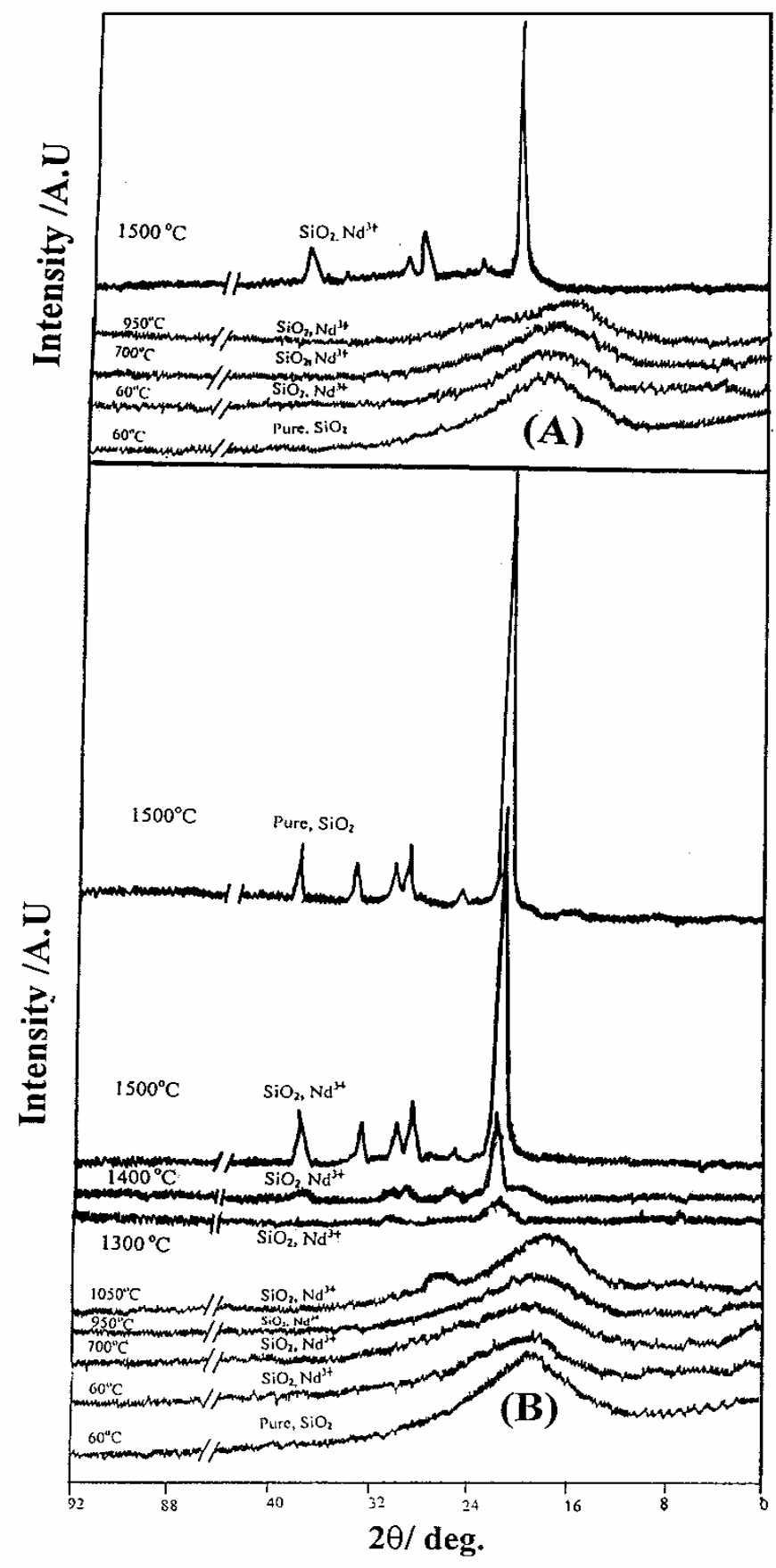

Fig. (1): XRD patterns of pure silica gel dried at $60^{\circ} \mathrm{C} \&$ heat-treated at $1500^{\circ} \mathrm{C}$ and silica gel doped with neodymium, dried at $60^{\circ} \mathrm{C} \&$ heat-treated from 700 upto $1500^{\circ} \mathrm{C}$, (A) type I \& (B) type II. 
Transmission electron micrographs of fracture surfaces of pure silica gel derived glasses and doped with $\mathrm{Nd}^{3+}$ ion are shown in Fig. (2 a-e). A distinct difference in ordering and coalescence of crystallite between pure sample (type II), and doped samples (type I and II), heattreated at different heating temperature appeared. Amorphous phase is observed at $700^{\circ} \mathrm{C}$ for doped sample (type II), as shown in Fig. (2 a), which shows particles with undefined shape and randomly distributed. The appearance of the aggregates might be as a result of the low solubility of the neodymium in silica [17]. While, by increasing the heat-treated temperature up to $1400^{\circ} \mathrm{C}$ for the same sample, smaller structural particles appeared and become nearer to each other as shown in Fig. (2 c and d). These observations might be due to that, at lower heattreatment temperature it rests some residual water and hydroxyl groups which prevent the density to increase. The gel gradually loosed some of its weight by increasing the firing temperature causing increase in its density, giving rise to the change from amorphous to crystalline phase. This result is in good agreement with the DTA and TGA results in this work and those published before by Battisha [18]. (e)
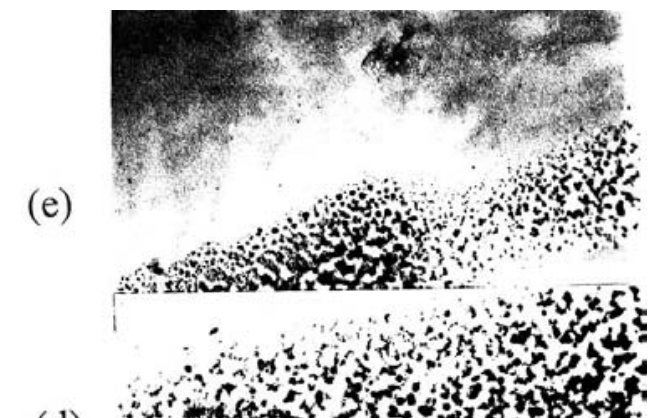

(d)

(c)

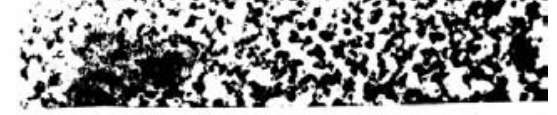

(b)

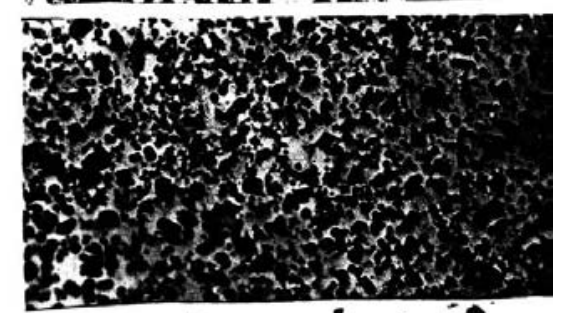

(a)
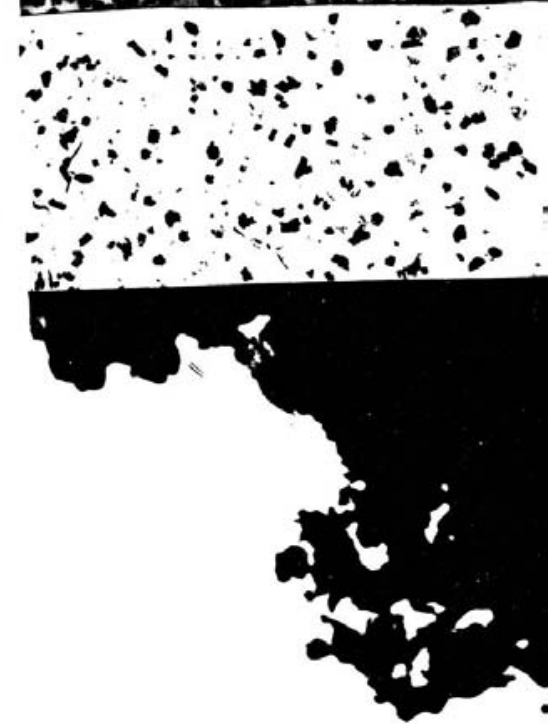

Fig. (2 a-e) TEM micrographs of silica gel doped with $\mathrm{Nd} 3+$ (type II) (a, c $\&$ d) heat treated at: a) 700 $(50000 \mathrm{X})$, c) $1400(80000 \mathrm{X})$ \& d) $1300^{\circ} \mathrm{C}(100000 \mathrm{X}),(\mathrm{b})$ pure sample (type II) heat treated at $1400^{\circ} \mathrm{C}(80000 \mathrm{X})$ and (e) doped sample (type I) heat reated at $1300^{\circ} \mathrm{C}$. 


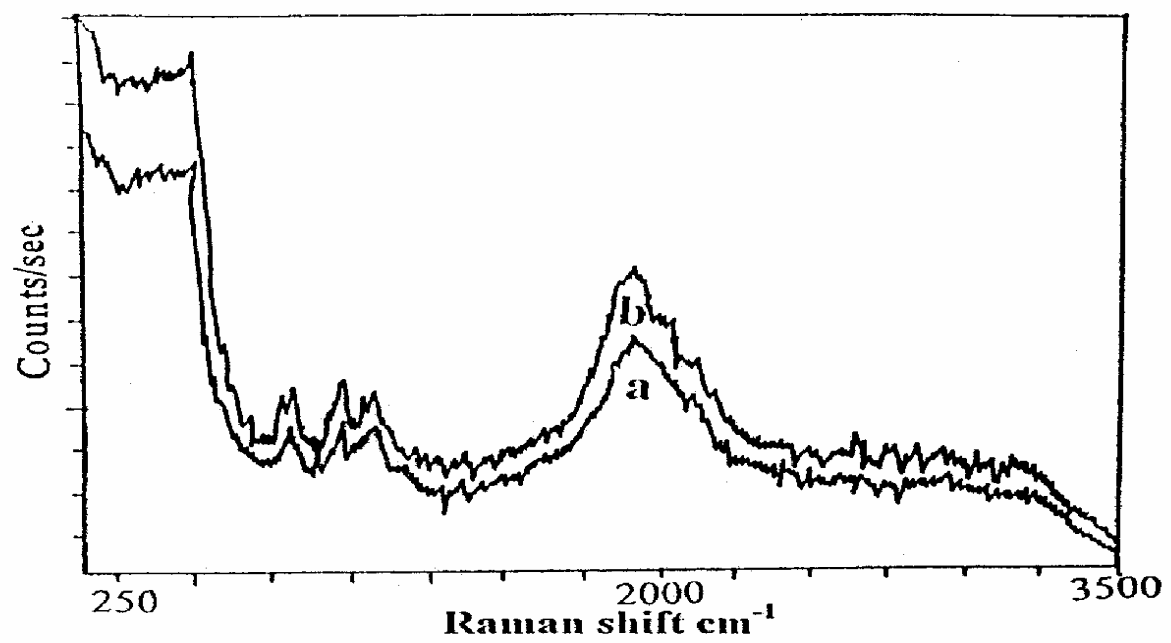

Fig. (3): Raman spectra of silica gel doped with $\mathrm{Nd}^{3+}$ and heat treated at $950^{\circ} \mathrm{C}:$ a) type I and b) type II.
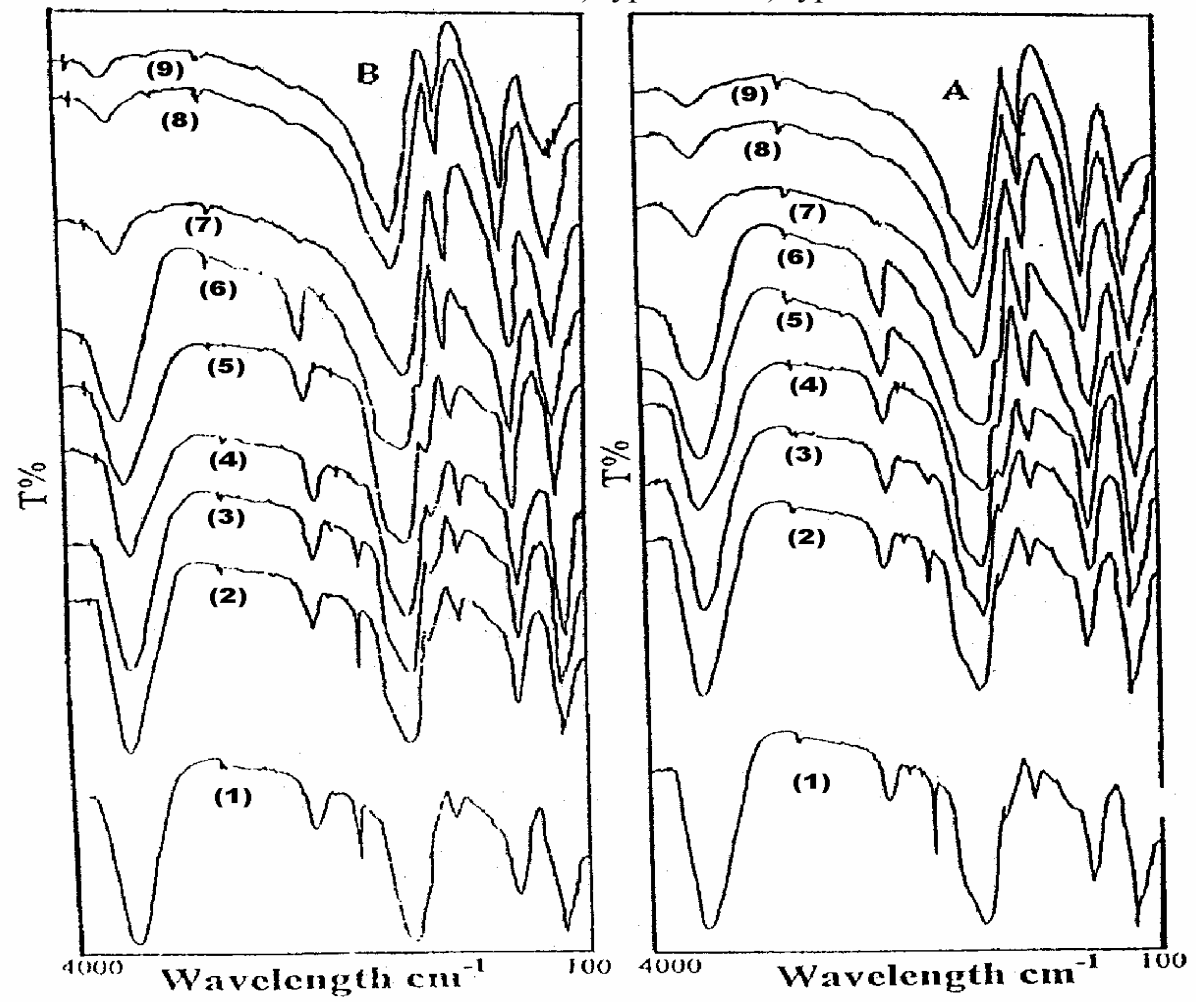

Fig. (4): Transmission FTIR spectrum of Silica gel doped with $\mathrm{Nd}^{3+}$, heat treated at $60^{\circ} \mathrm{C}$ for: 1) 2 days, 2) 21 days. and heat treated at: 3) $300^{\circ} \mathrm{C}$, 4) $500^{\circ} \mathrm{C}$, 5) $700^{\circ} \mathrm{C}, 6$ ) $\left.\left.850^{\circ} \mathrm{C}, 7\right) 950^{\circ} \mathrm{C}, 8\right) 1050^{\circ} \mathrm{C}$ and g) pure silica gel heat treated at $1050^{\circ} \mathrm{C}$. 
where, the structure collapses: The pore is expected to close and fuse together, a smooth material was obtained. These results confirmed the results obtained by XRD analysis. The electron diffraction patterns were analyzed, displaying faint rings. Particles smaller than $10 \mathrm{~nm}$ diameters were observed for samples doped with $\mathrm{Nd}^{3+}$ heat-treated at $1400^{\circ} \mathrm{C}$ (type I and II) shown in Fig. ( $2 \mathrm{f}$ and g).

Both Raman and FTIR spectra of the two prepared types I and II using acid catalyzed process, at constant heat treatment temperature $950^{\circ} \mathrm{C}$ for Raman and heat treated from 60 up to $1050^{\circ} \mathrm{C}$ for FTIR are shown in Figs. ( 3 a \& b) and $(4 \mathrm{a} \& \mathrm{~b})$, respectively. The major features of the Raman spectrum associated with network vibrational modes are the 520,800,1070, 1925 and $3425 \mathrm{~cm}^{-1}$ bands [19]. Corresponding FTIR bands of the two types material I and II are observed at about 470, 802, 985, 1097, 1384, 1636 and $3429 \mathrm{~cm}^{-1}$.

Hydroxyl groups are evident in the Raman and FTIR spectra, we observed bands at $1925 \mathrm{~cm}^{-1}$ assigned to $\mathrm{Si}-\mathrm{OH}$ stretching vibrations in the Raman spectrum, which disappeared in the FTIR spectrum. The band centered between 3400 and $3450 \mathrm{~cm}^{-1}$, corresponding to the fundamental stretching vibrations of different hydroxyl groups, decreases by heat-treatment up to $1050^{\circ} \mathrm{C}$ in the FTIR spectrum. This reveals that the $\mathrm{Si}(\mathrm{OH})_{4}$ is not converted into $\mathrm{SiO}_{2}$ in the initial state of preparing the material. This band seems broad and weak in the Raman spectrum, and then become stronger in the FTIR spectrum. This result is in agreement with previous coworkers [20], who found that for some group frequencies, the associated infrared bands are weak and the Raman bands strong, or vise versa. In addition, the presence of adsorbed water is indicated by the absorption band at $1636 \mathrm{~cm}^{-1}$, which is assigned to the bending mode of water molecules. There is also a noticeable decrease in the intensity of the $\mathrm{H}_{2} \mathrm{O}$ absorption in this band until it disappears at 950 and $1050^{\circ} \mathrm{C}$ for the two types. The peaks located at $1384 \mathrm{~cm}^{-1}$ in FTIR spectrum, which is assigned to vibrations of (TMOS, methoxy group and TEOS, ethoxy group) [21], were very unstable, it disappeared easily with temperature. Its absence from 500 up to $1050^{\circ} \mathrm{C}$ may be due to the completely hydrolyzed and no reesterification of the methoxy and ethoxy groups occurs during drying. The peaks at $1070 \mathrm{~cm}^{-1}$ (Raman) which changed to the strong and broad peaks at $1097 \mathrm{~cm}^{-1}$ (FTIR), are assigned to Si-O-Si assymetric stretching mode, it shifted to a higher wave number with increasing temperature in the FTIR spectrum, superimposed on this broad bands a shoulder at $985 \mathrm{~cm}^{-1}$. The 800 (Raman) and 802 (FTIR) $\mathrm{cm}^{-1}$ vibration is associated with symmetric Si-O-Si stretching or vibrational modes of ring structures. The 520 (Raman) and 470 (FTIR) $\mathrm{cm}^{-1}$ vibrations assign to Si-O-Si bending modes [22]. The 800 (Raman) and 802 (FTIR) $\mathrm{cm}^{-1}$ vibration is associated with symmetric Si-O-Si stretching or vibrational modes of ring structures. The increased intensity of the bands centered between 200 and $400 \mathrm{~cm}^{-1}$ may be due to a very strong modifying 
effect of the $\mathrm{Nd}^{3+}$ ions, which seems active. The excess of water at the gel-point after 2 and 4 days for type I and II dried at $60^{\circ} \mathrm{C}$ shown in Figs $(4$ a \& b) respectively, however, leads to the retention of methoxy and ethoxy groups in the samples. The excess of gelation time of type II than type I is probably due to more internal silanols in the near FTIR region and due presumably to their microporous nature, then type I may loses water easily than type II.
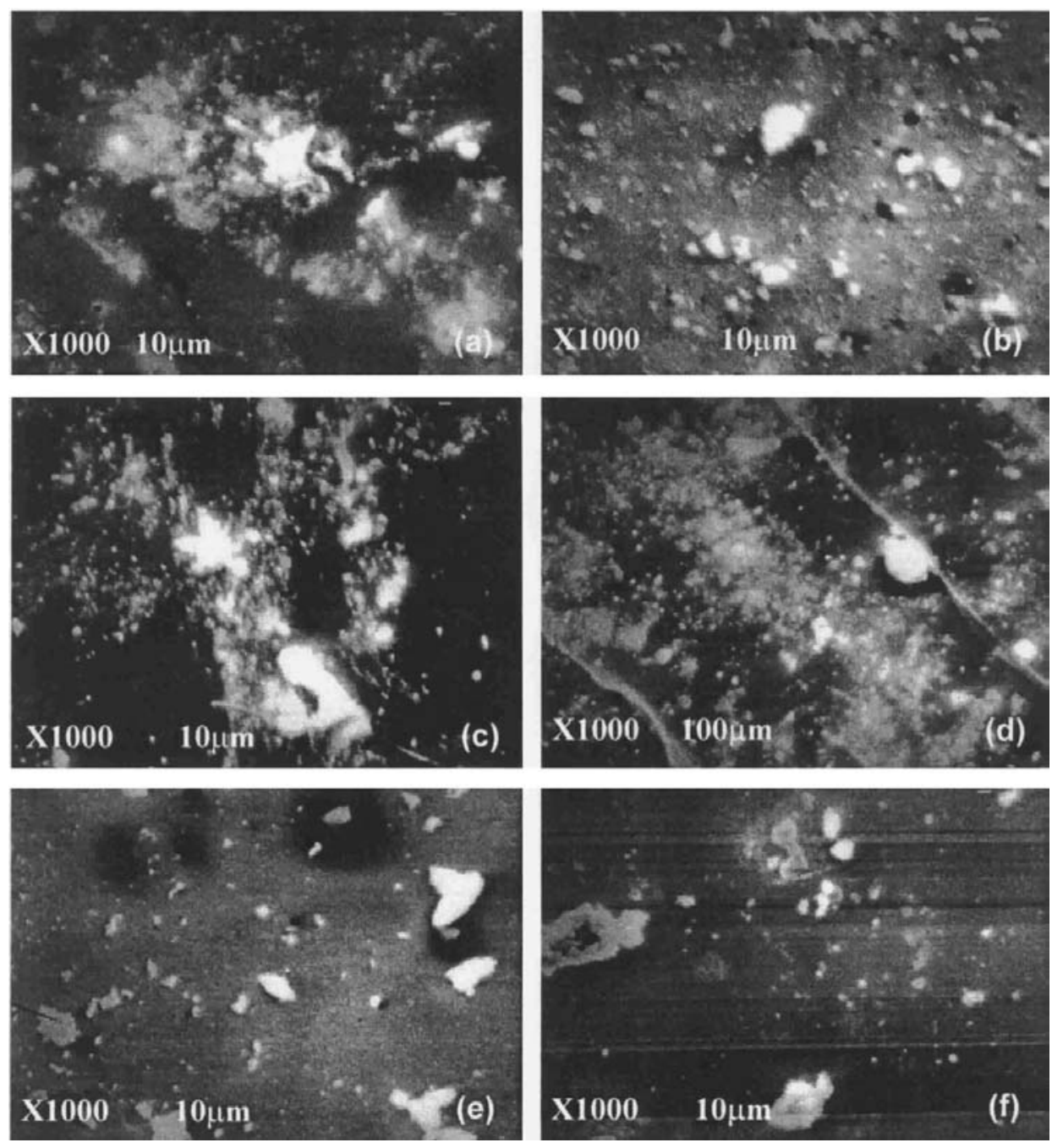

Fig. (5): SEM micrographs of silica gel doped with $\mathrm{Nd}^{3+}$, a \& b- dried at $60^{\circ} \mathrm{C}$ for 21 days (type I \& II), c \& d- heat treated at $500^{\circ} \mathrm{C}$ (type I \& II) and e \& f- heat treated at $700 \& 950^{\circ} \mathrm{C}$ (type I), (X1000).

SEM of silica gel derived glasses doped with $\mathrm{Nd}^{3+}$, dried at $60^{\circ} \mathrm{C}$ for 21 days, heat-treated at $500^{\circ} \mathrm{C}$ (type I\&II) and heat-treated at 700 and $950^{\circ} \mathrm{C}$ (type I), are shown in Figs. (5 a, b, c, d, e \& f), respectively. It is observe that, 
by using TMOS (type I) material we obtain more dense gel that retains less organic material than (type II), while the samples of (type I) leads to gels with finer and dense structure, figures $(5: \mathrm{a}, \mathrm{b})$. The surface morphology of the dried samples at $60^{\circ} \mathrm{C}$ for 21 days is less dense than the samples heat-treated at $500^{\circ} \mathrm{C}$ for both types I and II. This might be due to the existence of solvent and water molecules imbedded in the silica gel derived glasses, figures (5: a, b, c \&d). While a decrease in the cluster regardless the use of (type I or II) at $500^{\circ} \mathrm{C}$ appeared. The morphology changes from coarse scale to fine one by increasing the heat-treated temperature up to $950^{\circ} \mathrm{C}$ (type I), Figs. (5: a, c, e \& d). These morphology might be due to condensation, strengthening and densification of the gel at higher temperature [7]. Where at higher temperature the water content as well as solvent molecules showed drastic decrease giving rise to a relatively fine and dense material.

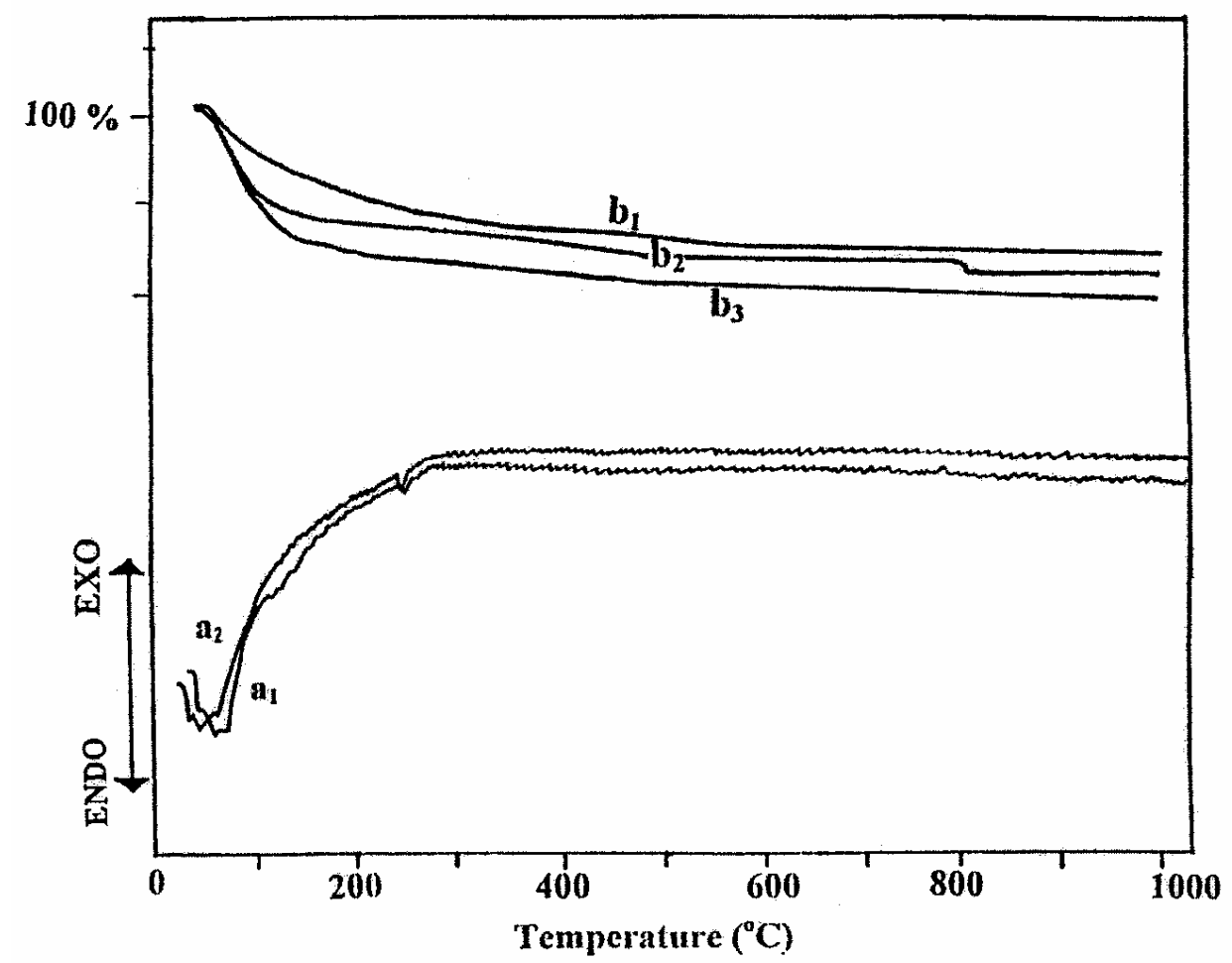

Fig. (6): TGA curves of $\left(b_{1}, b_{2} \& b_{3}\right)$ pure silica gel (type II) and silica gel doped with $\mathrm{ND}^{3+}$ (type I \& II) respectively, and DTA curves of $\left(\mathrm{a}_{1}\right.$ $\& \mathrm{a}_{2}$ ) pure silica gel and silica gel doped with $\mathrm{Nd}^{3+}$ (type II), all of them are dried at $60^{\circ} \mathrm{C}$.

When the gels are heated, the alkoxy and hydroxyl groups are removed by condensation reactions that cause the large weight loss illustrated in Figs. ( 6 a1, a2, b1, b2 \& b3) of the different thermal analysis (DTA) and the thermal gravitational analysis (TGA). Figs. (6 a1, a2) shows the DTA traces of pure 
silica gel and silica gel doped with $\mathrm{Nd}^{3+}$ (type II), both was dried at $60^{\circ} \mathrm{C}$ for 21 days. Two endothermic peaks system are observed, a big one around $700^{\circ} \mathrm{C}$ and a small one around $265^{\circ} \mathrm{C}$. The first might be attributed to the desorption of residual traces of water as a result of hydrolysis and condensation, while the second one might be attributed to decomposition and evaporation of traces organic residues. This effect is as obvious in the FTIR spectra. DTA studies by previous workers [19] have confirmed that the $100^{\circ} \mathrm{C}$ endothermic results from the desorption of the physically adsorbed water. The combustion losses using TGA experiments confirms the previous hypothesis resulting from the DTA. The calculated total weight loss of pure silica gel (type II) and silica gel doped with Nd3+ (types I \& II) shown in Figs. (6 b1, b2 \& b3) was [(11.5), (19) \& (21)] \%, [(14.5), (25) \& (28)]\% and [(19), (26) \& (29)]\% in the temperature intervals $\left(25-150^{\circ} \mathrm{C}\right),\left(150-600^{\circ} \mathrm{C}\right)$ and $\left(600-1000^{\circ} \mathrm{C}\right)$, respectively. The percentage weight loss attributed primarily to $\mathrm{H}_{2} \mathrm{O}$ and $\mathrm{OH}$ in the temperature intervals $\left(25-150^{\circ} \mathrm{C}\right)$, whereas, it is attributed to the organic compound in the temperature interval $\left(150-600^{\circ} \mathrm{C}\right)$. We can conclude that, doping the samples with neodymium enhance the percentage weight loss, while using TMOS decreasing it. These results are computable with the FTIR results where the peaks at 1600 and $3400 \mathrm{~cm}^{-1}$ decreased by increasing the heat treatment up to $1050^{\circ} \mathrm{C}$.

The prepared pure silica gel is colorless, while the silica gel containing $\mathrm{Nd}^{3+}$ has a violet color. Fig. (7) shows the transmission spectra of pure and doped silica gel prepared samples (type I \& II) with constant thickness $3 \mathrm{~mm}$. It is observed that, the pure prepared sample (a) at $60^{\circ} \mathrm{C}$ for 21 days (type I) has high transmission. No peak appeared in the Uv. Vis. While by doping the prepared samples at the same condition (b \& c) (type I \& II) with $\mathrm{Nd}^{3+}$ ion the transmission decreased, and many peaks appeared, their relative intensities have been related to the effect of neodymium ions in the silica gel glass. A notable feature of $\mathrm{Nd}^{3+}$ spectra is the asymmetry of the absorption lines, which may be attributed to systematic distortions of the octahedral sites of the $\mathrm{Nd}^{3+}$ ions [12]. It was observed from Figs. ( 7, b \& d) that, by increasing the heat treatment temperature of doped sample (type I) from $60^{\circ} \mathrm{C}$ up to $950^{\circ} \mathrm{C}$ the scattering increased and the transmission decreased, this might be due to the condensation and densification produced by increasing the heat treatment temperature causing totally different structure in this case, which may give a much smaller pore size. This result is in agreement with XRD, SEM, DTA and TGA results obtained in the present work and with previous workers [24]. 


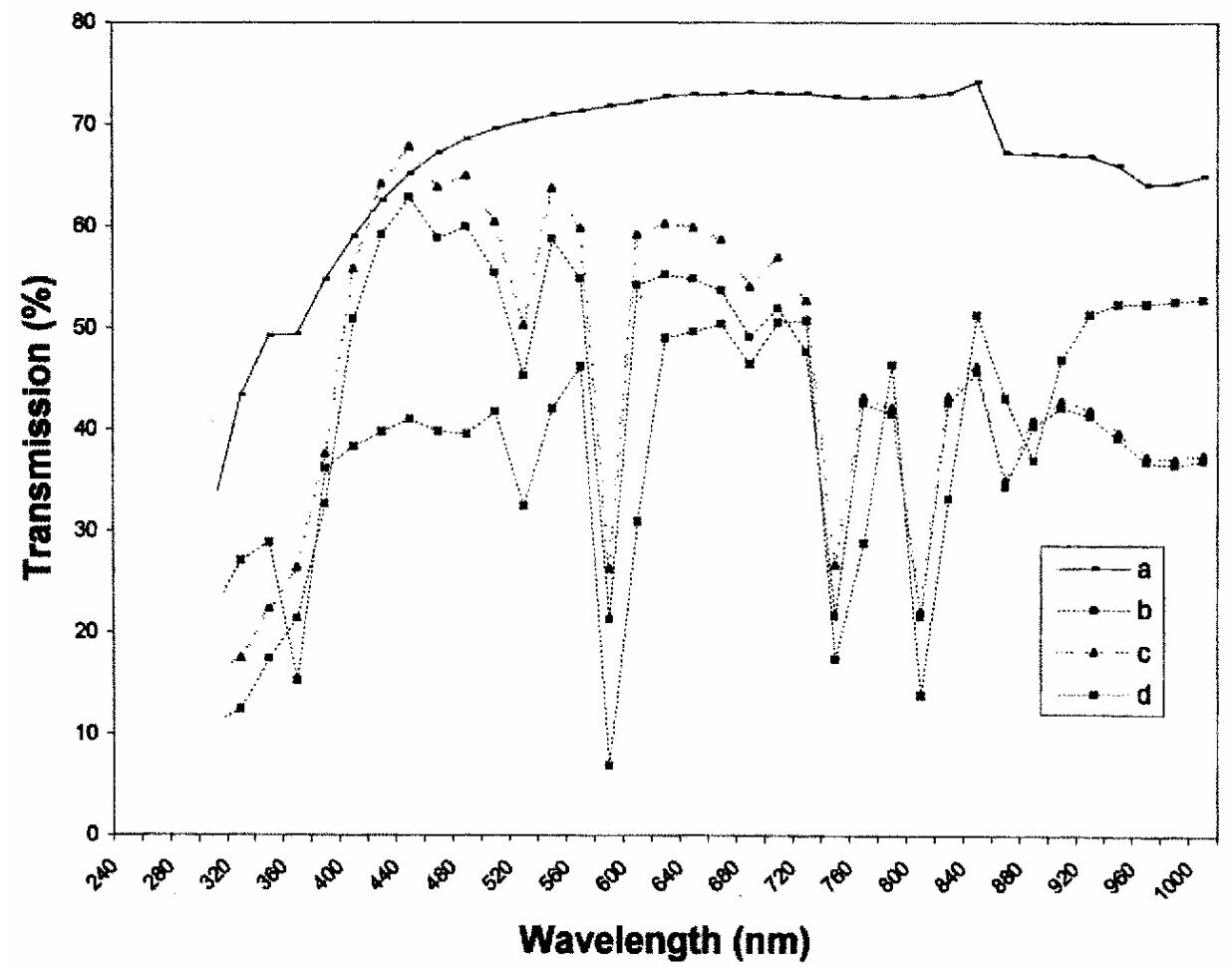

Fig. (7): The transmission spectra at $3 \mathrm{~mm}$ thick of: (a) pure silica gel dried at $60^{\circ} \mathrm{C}$ for 21 days, type $\left.\mathrm{I}, \mathrm{b}\right) \&$ c) silica gel doped with Neodimim, dried at $60^{\circ} \mathrm{C}$ for 21 days, type I \& II and d) doped sample type I, heat treated at $950^{\circ} \mathrm{C}$.

Figure (8) shows the PL measurements of silica gel doped with $\mathrm{Nd}^{3+}$ heat-treated in air for two hours at $1400^{\circ} \mathrm{C}$ type (I). The inset in Fig. (8) shows the PL of pure silica gel heat-treated in air for two hours at $1400^{\circ} \mathrm{C}$ type (I). PL bands of maximum in the blue green spectral region at 535 and $546 \mathrm{~nm}$ and other band of weak intensity at $590 \mathrm{~nm}$ were appeared for pure and doped samples. It is expected that, these PL bands are of pure silica gel. They are originating from Si-O-Si assymetric stretching appeared at $1070 \mathrm{~cm}^{-1}$ (Raman), which changed to the strong and broad peak at $1097 \mathrm{~cm}^{-1}$ (FTIR), and from defects such as impurities and E' centers [23]. While for the doped sample with $\mathrm{Nd}^{3+}$ bigger, sharper and intense bands at 875,889 and $900 \mathrm{~nm}$ in addition were detected due to $4 \mathrm{~F} 3 / 2$ to $4 \mathrm{I} 9 / 2$ transitions of $\mathrm{Nd}^{3+}$ ion. 


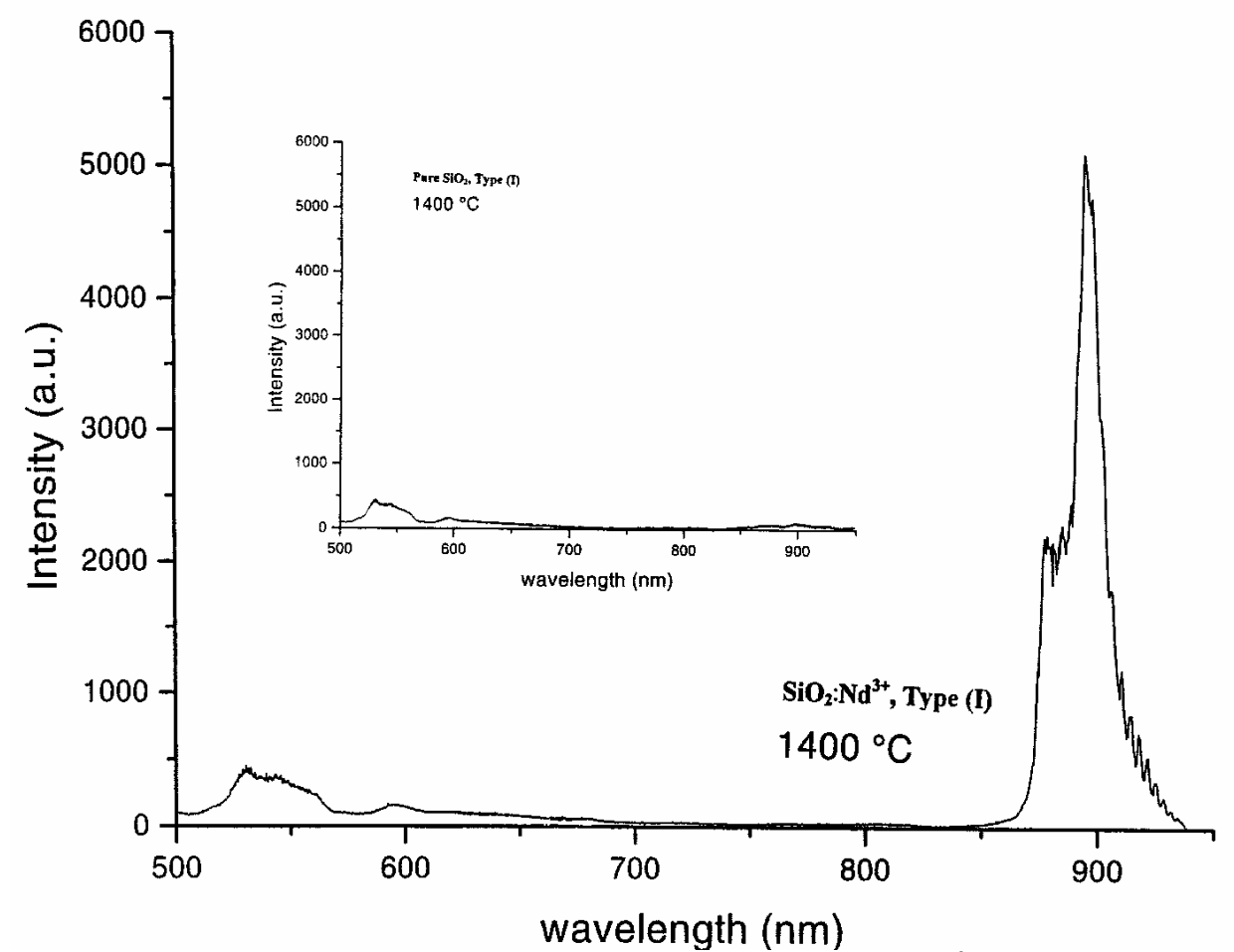

Fig. (8): Photoluminescence spectra of silica gel doped with $\mathrm{Nd}^{3+}$ heat-treated at $1400^{\circ} \mathrm{C}$ type II, the inset is for the photoluminescence of pure silica gel heat-treated at $1400^{\circ} \mathrm{C}$.

\section{Conclusions}

A simple sol-gel method was successfully used for the preparation of both pure silica gel derived glasses and doped with $\mathrm{Nd}^{3+}$ ion, using two different type precursors. The prepared samples were subjected to heat-treatment temperature for 2 hours ranging from 200 up to $1500^{\circ} \mathrm{C}$. The XRD studies showed that, by increasing the heat-treatment temperature the amorphous phase changed to $\alpha$-crystobalite phase. It was found that, doping the sample with $\mathrm{Nd}^{3+}$ decreases the crystallite size. The crystallite size was found to be as small as $10.4 \mathrm{~nm}$ at $1400^{\circ} \mathrm{C}$ for pure sample type II. The SEM observations confirmed the advantages of the sol gel process for obtaining amorphous materials at lower temperature and that; dense and more homogeneous materials were obtained at higher temperature. DTA and the TGA studies indicated the effect of $\mathrm{Nd}^{3+}$ doping on the enhancement of the weight loss, confirmed by the FTIR results. The Raman and FTIR spectra elucidate the bonding system of the constituent atoms and groups such as $\mathrm{Si}, \mathrm{O}$ and $\mathrm{OH}$ that throw light to the expected 
structure intense. The optical studies revealed that, the present of $\mathrm{Nd}^{3+}$ ion in the net-work silica gel glasses decreased the transmission, and many peaks appeared, their relative intensities have been related to the effect of $\mathrm{Nd}^{3+}$ ion. PL bands for pure sample heat-treated at $1400^{\circ} \mathrm{C}$ (type I) appeared in the blue green spectral region at 535,546 and $590 \mathrm{~nm}$. While in doped sample heat-treated at $1400^{\circ} \mathrm{C}$ (type I), new PL bands at $900 \mathrm{~nm}$ and two other bands at 875 and 889 $\mathrm{nm}$ appeared due to $4 \mathrm{~F}_{3 / 2}$ to $4 \mathrm{I}_{9 / 2}$ transitions of $\mathrm{Nd}^{3+}$ ion. The investigation showed that it is possible to incorporate neodymium cations into silica gel network in a condensation process by use of $\mathrm{Nd}_{2} \mathrm{O}_{3}$.

\section{Acknowledgements}

The author thanks Pr. Dr. Marco Bettinelli, Dr. Adolfo Speghini, Dipatimento Scientifico e Tecnologico, for the Photoluminescence measurement, Verona, Italy and Erica Viviani (Univ. Verona) for expert technical assistance.

\section{References}

1. T.Nakagawa and M.Soga, J. Non-Cryst.-Solids, 260, 167 (1999).

2. H.T.Sun, C.Cantalina, M.Faccio and M.Pelino, Thin Solid Films 269, 97 (1999).

3. S.V.Kalinin, L.I.Kheifets, A.I.Mamchik, A.G.Knot Ko and A.A.Vertegel, J.of Sol-Gel Science and Technology 15, 31 (1999).

4. F. Bentivegna, and M. Nyvit, J. of appl. Phys., 85 (4), 2270( 1999).

5. J. S. Q. Zeng and R. Greif, J. Matr. Res., (11), 8, 687 (1996).

6. T. Kawaguchi, J. Iura, N. Taneda, H. Hishikura and Y. Kokubu, J. of Non-Crystalline Solids, 82, 50 (1986).

7. J. V. L Beckers and SA. W. de Leeuw, J. of Non-Crystalline Solids, 261, 87 (2000).

8. J. Zarzycki, J. of Sol-Gel Science and Technology, 8, 17 (1997).

9. E. J. A. Pope and J. D. Mackenzie, J. Am. Ceram. Soc. 76 (5), 1325 (1993).

10. P. D. Maniar, A. Navrotsky, E. M. Rabinovich, J. Y. Ying and J. B. Benziger, J. of Non-Crystalline Solids, 124, 101 (1990).

11. S. Sakka, J. of Sol-Gel Science and Technology, 3, 69 (1994).

12. K. Gatterer, G. Pucker, H. P. Fritzer and S. Arafa, J. of NonCrystalline Solids, 176, 237 (1994).

13. M. Nogami and Y. Abe, J. of Sol-Gel Science and Technology, 8, 867 (1997). 
14. A. Bouajaj, M. Ferrari and M. Montagna, J. of Sol-Gel Science and Technology, 8, 391 (1997).

15. M. Nogami and Y. Abe, J. of Sol-Gel Science and Technology, 9, 139 (1997).

16. J. Mendez-Vivar and R. Mendoza-Serna, J. of Sol-Gel Science and Technology, 8, 235 (1997).

17. Y. Dimitriev, M. Bursukova, E. Kashchieva, V. Chernev and B. Samuneva, J. of Sol-Gel Science and Technology, 8, 935 (1997).

18. I. K. Battisha, Phys.Low-Dim. Struct. 7/8, 935 (2001).

19. C. J. Brinker and G. W. Scherer, "Sol-Gel science: The Physical and Chemical of Sol-Gel Processing", Academic Press, Inc., Boston, (1990), Ch. 9.

20. C. Marvin, Tobin, Laser Raman Spectroscopy Interpretation Of Raman Spectrum, Wiley Interscience, Inc, New York, (35), 1970.

21. J. Chul Ro and In J. Chung, J. of Non-Crystalline Solids, 130, 935 (1991).

22. C. J. Brinker, D. R. Tallant, E. P. Roth and C. S. Ashley, J. of NonCrystalline Solids, 82, 117 (1986).

23. K. W. Boer editor, Advances in Solar Energy, University of Delaware Newark, Delaware, Inc. Plenum Press New York. London, 3, 207 (1990).

24. T.Nakagawa and M.Soga, J.of Non-Crystalline Solids, 260, 167 (1999). 